It is important that these observations are put into context: the clinical case histories, all based on real patients, were selected to prompt value judgments to estimate the value placed by the correspondents on factors such as "antisocial behaviour"-criminal behaviour and drug or alcohol misuse. The general public, unlike the clinicians, have probably not considered in depth the implications of donor shortage; furthermore, the case histories had to be brief and oversimplified. It was, in part, for this reason that we arranged for two focus groups. There are methodological concerns too. We used quota rather than random sampling; random sampling is purer but requires more respondents and more resources. The quota sampling used has been found to be robust and consistent over time.

We are grateful to all those who helped by taking part in this survey. We thank Miss Jayne Folwarski, Queen Elizabeth Hospital, Birmingham, for facilitating the study and $\mathrm{Mr}$ Brian Gosschalk, managing director, MORI, for his help and support.

Contributors: JN initiated the project and developed the ideas with DA and PMacM; the questionnaires were developed with AM and MS, who conducted the focus groups and analysed the findings.

Funding: Liver Research Trust.

Conflict of interest: MORI was paid by Birmingham Liver Unit to carry out the study.

1 UKTSSA. Transplant activity 1996. Bristol:UKTSSA, 1996.

2 United Network for Organ Sharing, Annual report 1997. Richmond VA:UNOS, 1998

3 Hauptman PJ, O'Connor K. Procurement and allocation of solid organs for transplantation. N Engl J Med 1997;336:422-31.

4 Steinbrook R. Allocating livers-devising a fair system. $N$ Engl J Med 1997;336:436-8

5 Neuberger J, Lake J. Allocating donor livers. BMJ 1997;314:1140-1.

6 World Health Organisation. Guiding principles on human organ transplantation. Lancet 1991;337:1470-1.
7 Dixon J, Welch HG. Priority setting: lessons from Oregon. Lancet 1991;337:891-4

8 Smith R. Rationing health care: moving the debate forward. $B M J$ 1996;312:1553.

9 Light DW. The real ethics of rationing. $B M J$ 1997;315:112-5.

10 Lenaghan J. Central government should have a greater role in rationing decisions. The case for. $B M J$ 1997;314:967-70.

11 Harrison S. Central government should have a greater role in rationing decisions. The case against. BMJ 1997;314:970-3

12 Stewart J, Kendall E, Coote A. Citizens'juries. London: Institute for Publi Policy Research, 1994.

13 Peters TG, Kittur DS, Mcgaw LJ, First MR, Nelson EW. Organ donors and non-donors-an American dilemma. Arch Intern Med 1996;156:2419-24.

14 Council on Ethical and Judicial Affairs, American Medical Association. Ethical demand for liver transplantation. Clin Transplant 1997;11:49-55.

15 Eghtesad B, Bronsther O, Irish W, Casavilla A, Abu Elmagd K, van Thiel $\mathrm{D}$, et al. Disease gravity and urgency of need as guide-lines for liver allocation. Hepatology 1994;20:56-8.

16 Williams A. The rationing debate: rationing health care by age. The case for. BMJ 1997;314:820-2.

17 Grimley Evans J. The rationing debate: rationing health care by age. The case against. $B M J 1997 ; 314: 822-5$

18 Altman LK. Defending tough decisions in a case open to hindsight. New York Times 1995 August 15; (col 1).

19 Ferguson M, Ferguson R. Rescuing Prometheus: a policy proposal to alleviate excess considerations in the allocation of organs and other scarce medical resources among patients. Arch Intern Med 1995;155: 29-34.

20 Mullen MA, Kohut N, Sam M, Blendis L, Singer P. Access to adult liver transplantation-a survey and ethical analysis. Can Med Assoc J 1996:154:337-49.

21 Ubel P, Loewenstein G. Public perceptions of the importance of prognosis in allocating transplantable livers to children. Med Decis Making 1996;16:234-41.

22 Ahn J, Homberger J. Involving patients in the cadaveric kidney transplant allocation process: a decision-theoretic perspective. Management Sci 1996;42:629-41.

23 Wiesner RH, Lombardero M, Lake J, Everhart J, Detre K. Liver transplantation for end-stage alcoholic liver disease: an assessment of outcomes. Liver Transplant Surg 1997;3:231-9.

24 Neuberger J, Tang H. Relapse after transplantation. Liver Transplant Surg 1997;3:275-9.

25 Benjamin M. Transplantation for alcoholic liver disease: the ethical issues. Liver Transplant Surg 199;3:337-42.

26 Ubel PA. Transplantation in alcoholics: separating prognosis and responsibility from social biases. Liver Transplant Surg 1997;3:343-6.

(Accepted 6 April 1998)

\title{
Risk factors for development of sexually abusive behaviour in sexually victimised adolescent boys: cross sectional study
}

David Skuse, Arnon Bentovim, Jill Hodges, Jim Stevenson, Chriso Andreou, Monica Lanyado, Michelle New, Bryn Williams, Dean McMillan

\section{Abstract}

Objective: To identify factors that may increase the risk of a sexually victimised adolescent boy developing sexually abusive behaviour.

Design: Sexually victimised boys who had sexually abused other children were compared with sexually victimised boys who had not done so.

Setting: Social services departments in south east England were invited to refer sexually abused and sexually abusing boys to a London postgraduate teaching hospital.

Subjects: 25 adolescent boys aged between 11 years and 15 years and 11 months.

Main outcome measures: Adjusted odds ratios estimated from unconditional logistic regression.
Results: Unadjusted odds rations for witnessing (8.1) as well as experiencing (18.0) intrafamilial violence and discontinuity of care (7.2) discriminated boys who had sexually abused from others who were solely victims of sexual abuse. Only the adjusted odds ratios for witnessing intrafamilial violence (39.7)

discriminated the two groups.

Conclusions: The risk of adolescent boys who have been victims of sexual abuse engaging in sexually abusive behaviour towards other children is increased by life circumstances which may be unrelated directly to the original abusive experience, in particular exposure to a climate of intrafamilial violence. Our findings have implications for the management of boys found to have been sexually abused and raise important questions about the possibility of secondary prevention of subsequent abusive behaviour in those at greatest risk.
Behavioural Sciences Unit, Institute of Child Health, London WC1N 1EH

David Skuse, professor of behavioural sciences Bryn Williams, research psychologist Dean McMillan, research assistant

continued over

BMJ 1998;317:175-9 
Department of Psychological Medicine, Great Ormond Street Hospital for Sick Children NHS Trust, London WC1N 3JH

Arnon Bentovim, homorary consultant child psychiatrist

Jill Hodges,

consultant child psychotherapist Chriso Andreou, child psychotherapist Monica Lanyado, child psychotherapist Michelle New, clinical psychologist

Department of Psychology, University of Southampton, Southampton SO17 1RJ

Jim Stevenson, professor of psychology Correspondence to: Professor Skuse dskuse@ich.ucl.ac.uk

\section{Introduction}

A substantial proportion of both boys and girls are sexually abused during childhood. Prevalence figures vary (boys: $3 \%$ to $37 \%$; girls: $6 \%$ to $62 \%$ ), ${ }^{12}$ but even the most conservative estimates indicate this to be an important public health issue. Such experiences have been linked to mental health disorders in later life, including depression and sexual dysfunction. ${ }^{3}$ Society is increasingly concerned about these worrying figures and there have been calls to develop strategies aimed at the prevention of paedophilic behaviour. ${ }^{4}$

Some have argued that the very experience of sexual victimisation puts an individual at risk of becoming a sexual abuser. ${ }^{5}$ Studies report high rates of former sexual victimisation among adult sex offenders, but most victims do not go on to abuse. ${ }^{6}$ We hypothesised that an individual who has been sexually victimised during childhood would go on to abuse only if other risk factors were also present. We focused exclusively on adolescent boys as most perpetrators are male $^{7}$ and a pattern of sexual offending is often established in adolescence. ${ }^{8}$

We compared two groups of boys matched for age who had been victims of sexual abuse. One of the groups had subsequently sexually abused other children, the other had not. A wide range of interpersonal and intrapersonal variables that could potentially discriminate between these groups was measured. The choice of measures was based on specific hypotheses about predisposing factors, derived from clinical experience and a review of the relevant literature. We undertook an intensive (with respect to the individual concerned) and extensive (with respect to the range of sources of information about potential risk factors) investigation of the risk of sexually abusive behaviour in sexually victimised adolescent boys.

\section{Subjects and methods}

A London postgraduate teaching hospital invited social services departments in south east England to refer boys aged between 11 years and 15 years and 11 months who had been victims of sexual abuse, including those who had in addition sexually abused other children. In total 78 boys were referred to the study, of whom 32 had abused others. Twenty five boys were selected to enter the full assessment procedure. This sample consisted of 11 boys who had sexually abused other children and 14 who had not. Reasons for exclusion included practical constraints on the completion of the assessment procedure, usually connected with travel arrangements, overtly aggressive behaviour, and denial of documented sexually abusive behaviour. Only participants who took part in the full assessment are reported here. Ethical approval for the study was given by the Research Ethics Committee of Great Ormond Street Hospital for Sick Children NHS Trust and the Institute of Child Health.

In the first stage of the assessment information was collected on intelligence (Wechsler intelligence scale for children ${ }^{9}$ ), pubertal status, socioeconomic circumstances, and friendships (network relationship inventory ${ }^{10}$ ) (BW). Socioeconomic circumstances were measured with the Osborne social index ${ }^{11}$; those obtaining a score of above 50 were considered to live in adversity compared with the general population. Pubertal status (based on Tanner staging ${ }^{12}$ ) was assessed by self report (from photographs) of testicular development and pubic hair growth. Each characteristic was scored from 1 (prepubertal) to 5 (postpubertal). Peers' perceptions of the boys were obtained by sociometry. ${ }^{13} 14$ The technique requires classmates to complete checklists about the popularity and personal characteristics of all other pupils in the class. It entailed measurements in 25 schools, with a total of about 500 pupils. These methods have not previously been used in studies of sexually abusive children.

The second stage consisted of 3 months of individual weekly psychotherapy sessions, ${ }^{15}{ }^{16}$ conducted by psychoanalytically trained child psychotherapists (ML, CA). Six sessions were semistructured with standardised instruments, including measures of attachment (adult attachment interview ${ }^{17}$ ) and hostility (Buss-Durkee hostility-guilt inventory ${ }^{18}$ ). A grounded theory approach was applied to verbatim transcripts of the adult attachment interview to derive childhood themes relating to history of care and maltreatment. ${ }^{19}$ Six less structured sessions covered the boy's life history, his own sexually abusive behaviour, and his sexual fantasies. Boys' reports of their early experiences were verified from independent sources including interviews with others (mother, social workers) and from social services records. No boys revealed having engaged in sexually abusive acts that were previously unknown.

Birth mothers were interviewed about their life history $(\mathrm{MN})$, including their experience of maltreatment, with an interview designed for the study. Current carers were seen if a boy was no longer living with his family of origin. Mothers also completed the Beck depression inventory. ${ }^{20}$

Statistical methods-The two groups were compared with $t$ tests, Mann-Whitney $\mathrm{U}$ tests, contingency tables, and odds ratios. On the basis of the psychotherapeutic assessment and a review of the relevant literature we identified 13 potential risk factors and calculated unadjusted odds ratios and 95\% confidence intervals for each of these. Definitions of the potential risk factors are given in table 1 . The unadjusted odds ratios indicated that three of the 13 variables were significant, the lower 95\% confidence limit being greater than 1. A second stage of analysis used unconditional logistic regression to determine adjusted odds ratios.

\section{Results}

There were no significant differences between the two groups on most of the measures of personal and familial characteristics (table 2), although those victims who had sexually abused reported more advanced puberty in terms of testicular development (Mann-Whitney $\mathrm{U}$ test $\mathrm{z}=-2.42 ; \mathrm{P}=0.02$ ). No differences were found between the groups in terms of their experience of sexual victimisation (based on personal accounts and contemporaneous records). Severity of sexual abuse was ascertained from evidence of penetration $\left(\chi^{2}=0.00 ; 1 \mathrm{df} ; \mathrm{P}=0.97\right)$, duration (Mann-Whitney $\mathrm{U}$ test $\mathrm{z}=0.71 ; \mathrm{P}=0.48$ ), whether the abuse was within or outside the family $\left(\chi^{2}=0.00 ; 1 \mathrm{df} ; \mathrm{P}=0.97\right)$, and the 


\begin{tabular}{|c|c|}
\hline Potential risk factor & Description \\
\hline Experiencing intrafamilial violence ${ }^{*}$ & Report by boy during adolescent adaption of adult attachment interview ${ }^{17}$ of recurrent acts of physical abuse \\
\hline Witnessing intrafamilial violence $^{\star}$ & $\begin{array}{l}\text { Report in adult attachment interview }{ }^{17} \text { of exposure to recurrent acts of marital violence or physical abuse of } \\
\text { siblings, or both }\end{array}$ \\
\hline Rejection by family* & Report by boy in adult attachment interview ${ }^{17}$ of rejection, emotional abuse, or neglect \\
\hline Discontinuity of care ${ }^{*}$ & $\begin{array}{l}\text { Report in adult attachment interview }{ }^{17} \text { of marital breakdown, being in care of local authority, in children's home or } \\
\text { foster home }\end{array}$ \\
\hline Rejected by peers & $\begin{array}{l}\text { Calculated by using sociometry }{ }^{1314} \text { and designated as present if boy's rating of peer inclusion was }>1 S D \text { below } \\
\text { mean for whole class }\end{array}$ \\
\hline Generalised sense of grievance & $\begin{array}{l}\text { Present if boy scored >1SD above population mean on resentment scale of Buss-Durkee hostility-guilt inventory }{ }^{18} \\
\text { or rating of generalised grievance was made by boy's psychotherapist, or both }\end{array}$ \\
\hline Poor identification with father figure/s & Rating made by psychotherapist of extent to which boy identified with his father figure/s \\
\hline $\begin{array}{l}\text { Absence of a non-abusive male attachment } \\
\text { figure }\end{array}$ & Scored as present if all father figures in boy's life were emotionally/physically or sexually abusive, or both \\
\hline Mother was sexually abused in childhood ${ }^{*}$ & Report by mother during maternal interview of having been sexually abused in childhood \\
\hline Maternal depression & Present if mother scored $>15$ on Beck depression inventory ${ }^{20}$ \\
\hline Poor sibling relationship & $\begin{array}{l}\text { Present if boy scored }>1 S D \text { above mean on negative sibling support subscale of network relationship inventory }{ }^{10} \text { or } \\
>1 \text { SD below mean of positive sibling support subscale }\end{array}$ \\
\hline Mother was physically abused in childhood ${ }^{*}$ & Report by mother during maternal interview of having been physically abused in childhood \\
\hline Low levels of guilt & $\begin{array}{l}\text { Present if boy scored }>1 S D \text { in direction of low guilt on guilt subscale of Buss-Durkee hostility-guilt inventory }{ }^{18} \text { or } \\
\text { guilt rated as not present in adult attachment interview }{ }^{17}\end{array}$ \\
\hline
\end{tabular}

number of perpetrators involved (Mann-Whitney U test $\mathrm{z}=0.40 ; \mathrm{P}=0.69$ ).

We then analysed specific risk factors, hypothesised to distinguish the groups. Unadjusted odds ratios and $95 \%$ confidence intervals were calculated for each of 13 variables (table 3). Three of the 13 factors were associated with an increased risk of being in the sexually abusive group: experiencing intrafamilial violence, witnessing intrafamilial violence, and discontinuity of care. All related to events that preceded the sexually abusive behaviour that led to referral. All of the 11 boys in the abusers group had either experienced intrafamilial violence (two) or witnessed violence (one), or both (eight). Among the 14 boys in the victim only group, two had experienced violence, two had witnessed it, and two were in both categories. Discontinuity of care had been experienced by six abusers and two victims.

The three significant risk factors were then assessed further in a series of unconditional logistic regressions. The measure of testicular development was also entered in the regression as the distribution of scores differed significantly between the two groups. The logistic regression was run twice. On the first occasion, testicular development and all three significant risk factors were entered simultaneously. On the second occasion "experiencing intrafamilial violence" was excluded as it made no independent contribution to the variance in outcome. In the second regression, witnessing intrafamilial violence emerged as significant (adjusted odds ratio $39.7 ; 1.1$ to 1472.6 ), and discontinuity of care approached significance $(15.0 ; 0.9$ to 245.2).

\section{Discussion}

This study has found adolescent male victims of sexual abuse who have abused other children can be discriminated from those who have not done so in terms of life events that are unrelated directly to the experience of sexual victimisation. The risk of becoming an abuser was not found to be related to the severity of the victimisation experience, but the risk that is independ- ently associated with having been a victim of sexual abuse cannot be determined from this study design. Accordingly the findings are applicable only to boys who have been sexually abused. In addition, as the study focused on adolescent perpetrators the findings may apply only to boys who began abusing before or during adolescence. It is perhaps surprising that witnessing rather than experiencing intrafamilial violence seemed to be the most potent risk factor, although many boys were exposed to both risks. At this

Table 2 Personal and familial characteristics of sample of sexually abused adolescent boys. Values are means (SD)

\begin{tabular}{|c|c|c|c|}
\hline Demographic factor & $\begin{array}{l}\text { Victim only } \\
(n=14)\end{array}$ & $\begin{array}{l}\text { Victim and perpetrator } \\
\qquad(\mathrm{n}=11)\end{array}$ & $P$ value \\
\hline Testicular development (Tanner staging ${ }^{12}$ ) & $2.6(1.2)$ & $3.9(1.0)$ & $0.02^{*}$ \\
\hline Pubic hair growth (Tanner staging ${ }^{12}$ ) & $3.0(1.0)$ & $3.6(0.8)$ & $0.11^{*}$ \\
\hline Age (years) & $13.1(1.7)$ & $14.1(1.3)$ & $0.12 \dagger$ \\
\hline $\begin{array}{l}\text { Socioeconomic adversity index score } \\
\left(\text { (Osborne social index }{ }^{11}\right)\end{array}$ & $49.4(7.5)$ & $46.1(5.0)$ & $0.24 \dagger$ \\
\hline Intelligence quotient (Wechsler scale ${ }^{9}$ ) & $91.6(15.9)$ & $85.4(11.4)$ & $0.28 \dagger$ \\
\hline
\end{tabular}

*Analysed with Mann-Whitney U tests. †Analysed with $t$ tests.

Table 3 Unadjusted odds ratio for potential risk factors for sexually abused adolescent boys becoming abusers themselves

\begin{tabular}{|c|c|c|c|}
\hline \multirow[b]{2}{*}{ Potential risk factor } & \multicolumn{2}{|c|}{ No exposed to risk factor } & \multirow[b]{2}{*}{$\begin{array}{l}\text { Unadjusted odds } \\
\text { ratio }(95 \% \mathrm{CI})\end{array}$} \\
\hline & $\begin{array}{l}\text { Victim only } \\
(n=14)\end{array}$ & $\begin{array}{c}\text { Victim and } \\
\text { perpetrator }(n=11)\end{array}$ & \\
\hline Experiencing intrafamilial violence & 5 & 10 & 18.0 (1.8 to 184.7$)$ \\
\hline Witnessing intrafamilial violence & 5 & 9 & $8.1(1.2$ to 53.2$)$ \\
\hline Rejection by family & 8 & 10 & $7.5(0.7$ to 75.7$)$ \\
\hline Discontinuity of care & 2 & 6 & $7.2(1.1$ to 48.6$)$ \\
\hline Rejected by peers & 3 & 5 & $3.1(0.5$ to 17.5$)$ \\
\hline Generalised sense of grievance & 4 & 6 & $3.0(0.6$ to 15.8$)$ \\
\hline Poor identification with father figure/s & 4 & 6 & 3.0 (0.6 to 15.8$)$ \\
\hline Absence of a non-abusive male attachment figure & 9 & 9 & $2.5(0.4$ to 16.4$)$ \\
\hline Mother was sexually abused in childhood & 6 & 7 & $2.3(0.5$ to 11.8$)$ \\
\hline Maternal depression & 6 & 6 & $1.6(0.3$ to 7.8$)$ \\
\hline Poor sibling relationship & 5 & 5 & $1.5(0.3$ to 7.5$)$ \\
\hline Mother was physically abused in childhood & 7 & 6 & $1.2(0.2$ to 5.8$)$ \\
\hline Low levels of guilt & 13 & 10 & $0.8(0$ to 13.9$)$ \\
\hline
\end{tabular}


stage it may be more useful to conceptualise this influence in terms of a climate of intrafamilial violence, which may or may not have directly involved the boy as a victim. An experience of discontinuity of care may also be important in predisposing sexually abused boys to abuse others, although with this small sample the adjusted odds ratio fell just short of significance. Just why these experiences are discriminating needs further investigation; at this stage we are unable to identify causal mechanisms. The findings are, however, in line with those from other recent research. For example, Ryan et al reported that $63 \%$ of adolescent offenders had witnessed intrafamilial violence and $56 \%$ had experienced the loss of a parental figure. ${ }^{21}$

\section{Limitations}

The research reported here was largely exploratory and the results require independent replication. Limitations include the small sample size; this reflects the considerable labour involved in the assessment procedure, which was both more extensive and intensive than any previous comparable investigation. Replication of the findings with a substantially larger sample is necessary. A small sample size reduces power and hence increases the likelihood of failing to find a significant difference that "really exists" (a type II error). The fact we were able to identify significant differences between our groups is therefore all the more compelling, unless a systematic bias, which was correlated with the risk factors, independently accounted for group differences. Such a potential bias includes the possibility that abusing boys were more likely to reveal, or claim, that they had been exposed to the risk factors. Systematic examination of information from independent sources (contemporaneous social service records, social workers, mothers) enabled us to refute that explanation for our findings.

The correct assignment of boys to perpetrating and non-perpetrating groups is difficult given the reluctance of sexual abusers to reveal their behaviour. The design of the study incorporated an intensive psychotherapeutic investigation to maximise the possibility of correct assignment. We recognise there remains the possibility of misclassification. Boys who were not sexually abusive at assessment may develop such behaviour in the future. Our findings can only indicate an increased risk of abusive behaviour occurring before the age of 16 years, and there may be an increased risk independently associated with sexual maturation. Finally, the sample was by necessity highly selected, consisting of boys whose abuse (and abusive behaviour) had been revealed and who were in contact with social services. So far as we have been able to ascertain, referrals were nevertheless a representative sample of all boys in the appropriate age range seen by cooperating social services departments during the period of recruitment. Bias due to selection after referral is unlikely to account for our findings.

\section{Conclusion}

This study provides evidence that boys who are victims of sexual abuse are more likely to become abusers of other children themselves in early adolescence if they have witnessed intrafamilial violence, an objectively verifiable risk factor which is unrelated to the
- The risk of sexually abused boys in early adolescence abusing other children may be associated with experiences in early life that are independent of sexual victimisation

- Exposure to persistent violence within the family may be a particularly important risk factor

- Management of sexually abused boys should take into account the impact of early life experiences that may be associated with increased risk with a view to the secondary prevention of sexually abusive behaviour

experience of sexual victimisation. The impact of marital violence on the emotional and behavioural development of children is a subject that requires greater attention than it has been given so far. At this stage, however, it may be more appropriate to view a climate of violence as conferring an increased risk, whether or not the boy is a direct victim of the physical abuse. These findings have implications for the management of vulnerable youths by statutory agencies who are dealing with sexually abused children. While it would be inappropriate to "label" a child a potential abuser just because he has been exposed to intrafamilial violence, our data do imply that relatively greater support may need to be given to boys at high risk with a view to averting future abusive behaviour.

We acknowledge the time and energy spent during the course of the study by the boys themselves, their families, and their social workers. We also thank Jennifer Smith, Joanne Newbolt, Rikki South, Elinore Percy, and Richard Reynolds for their help with the project.

Contributors: $\mathrm{DS}, \mathrm{AB}, \mathrm{JH}$, and $\mathrm{JS}$ were responsible for the design of the study. The psychotherapeutic investigation was conducted by $\mathrm{CA}$ and $\mathrm{ML}$ in collaboration with $\mathrm{JH}$. MN interviewed the mothers, and BW conducted the assessments in the first stage of the study, including the sociometry. $\mathrm{DS}, \mathrm{AB}, \mathrm{JH}$, JS, CA, ML, MN, and BW generated the hypotheses about the predisposing risk factors. DS, JS, and DM were primarily responsible for the data analysis and the drafting of the paper.

Funding: Department of Health.

Conflict of interest: None.

1 Dhaliwal GK, Gauzas L, Antonowicz DH, Ross RR. Adult male survivors of childhood sexual abuse: prevalence, sexual abuse characteristics and long-term effects. Clin Psychol Rev 1996;16:619-39.

2 Peters SD, Wyatt GE, Finkelhor D. Prevalence. In: Finkelhor D, ed. A source book on child sexual abuse. Beverly Hills: Sage Publications, 1986:15-59.

3 Beitchman JH, Zucker KJ, Hood JE, da Costa GA, Akman D, Cassavia E. A review of the long term effects of child sexual abuse. Child Abuse Neglect 1992;16:101-18.

4 Ryan G. Perpetration prevention: primary and secondary. In: Ryan G, Lane S, eds. Juvenile sexual offending:causes, consequences and correction. San Francisco: Jossey-Bass Publications, 1997:433-54.

5 Freeman-Longo RE. The impact of sexual victimisation on males. Child Abuse Neglect 1986;10:411-4.

6 Watkins B, Bentovim A. The sexual abuse of male children and adolescents: a review of current research. J Child Psychol Psychiatry 1992;33:197-248.

7 Smith M, Bentovim A. Sexual abuse. In: Rutter M, Taylor E, Hersov L, eds. Child and adolescent psychiatry: modern approaches. 3rd ed. Oxford: Blackwell Scientific Publications, 1994:230-51.

8 Groth AN, Longo RE, McFadin JB. Undetected recidivism among rapists and child molesters. Crime Delinq 1982;28:450-8.

9 Wechsler D. The Wechsler intelligence scale for children - manual. New York: Psychological Corporation, 1992

10 Furman W, Buhrmester D. Children's perceptions of the personal relationships in their social networks. Dev Psychol 1985;21:1016-24

11 Osborne AF. Assessing the socio-economic status of families. Sociology 1987;21:429-48. 
12 Tanner JM. Foetus into man:physical growth from conception to maturity. 2nd ed. Ware, Hertfordshire: Castlemead Publications, 1989.

13 Asher SR, Dodge KA. Identifying children who are rejected by their peers. Dev Psychol 1986;22:444-9.

14 Parkhurst JT, Asher SR. Peer rejection in middle school: subgroup differences in behavior, loneliness and interpersonal concerns. Dev Psychol 1992;28:231-41.

15 Hodges J, Lanyado M, Andreou C. Sexuality and violence: preliminary clinical hypotheses from the psychotherapeutic assessments in a research programme on young sexual offenders. J Child Psychother 1994;20: 283-308.

16 Lanyado M, Hodges J, Bentovim A, Andreou C, Williams B. Understanding boys who sexually abuse other children: a clinical illustration. Psychoanal Psychother 1995;9:231-42.
17 George C, Kaplan N, Main M. Adult attachment interview. Berkely, California: Berkley Department of Psychology, 1985

18 Buss AH, Durkee A. An inventory for assessing different kinds of hostility. J Clin Psychol 1957;21:343-49.

19 Glaser BG, Strauss AL. The discovery of grounded theory: strategies for quali tative research. London: Weidenfield and Nicolson, 1967.

20 Beck AT, Steer RA. Beck hopelessness scale manual. San Antonio, Texas: Psychological Corporation, Harcourt Brace Jovanovich, 1987.

21 Ryan G, Miyoshi TJ, Metzner JL, Krugman RD, Fryer GE. Trends in national sample of sexually abusive youths. J Am Acad Child Adolesc Psychiatry 1996;35:17-25.

(Accepted 6 April 1998)

\title{
Facial structure in the sudden infant death syndrome: case-control study
}

\author{
Karen Rees, Anne Wright, Jean W Keeling, Neil J Douglas
}

The cause of the sudden infant death syndrome is unclear. Polygraphic recordings of 30 infants who subsequently died of the syndrome showed a significant increase in mixed and obstructive apnoeas compared with well matched controls. ${ }^{1}$ Postmortem examination suggests upper airway narrowing in victims of the syndrome. The decreased number of cases of sudden infant death syndrome after advice to put infants to sleep supine suggests a posture dependent cause, and recent evidence suggests that upper airways of sleeping infants are more widely patent supine than prone. ${ }^{2}$ Thus sleeping supine might decrease obstructive apnoeas.

An increased frequency of sudden infant death syndrome and apparent life threatening events in infants has been found in the families of patients with the obstructive sleep apnoea/hypopnoea syndrome. ${ }^{34}$ We found that retroposition of the maxilla was a common feature in families who had both the obstructive sleep apnoea/hypopnoea and sudden infant death syndromes. ${ }^{3}$ We also found that obstructive apnoeas in adult family members of patients with the obstructive sleep apnoea/hypopnoea syndrome were related to retroposition of the maxilla and mandible. $^{5}$

We therefore tested the hypothesis that victims of the sudden infant death syndrome have backset maxillae and mandibles, which would predispose them to narrowing and occlusion of their upper airways.

\section{Subjects, methods, and results}

We examined differences in facial bone structure between 15 consecutive victims of the sudden infant death syndrome and 15 control infants who had died of explained causes. Each case was matched to a control infant aged within one postnatal month of the case (mean age 5 months, range 1-10 months). Lateral cephalographs taken at necropsy were examined for the maxillary position (the sella-nasion-subspinale angle) and the mandibular position (the sella-nasionsupramentale angle) (figure). These two angles have been shown to differ between first degree relatives of patients with sleep apnoea and the normal population. ${ }^{5}$ Measurements were recorded twice for each sub-

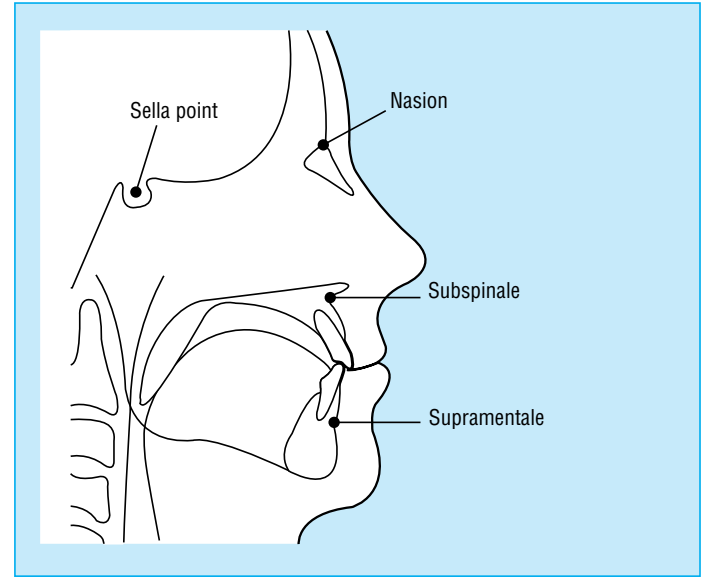

Skeletal reference points on schematic lateral cephalometric radiograph. Sella point is the midpoint of the sella turcica, the nasion is the most anterior point of the frontonasal suture, the subspinale is the most posterior point on the anterior contour of the upper alveolar process, and the supramentale is the most posterior point on the anterior contour of the lower alveolar process

ject by one observer blind to cause of death, and the average values were taken. The coefficient of variation for repeat measurements within individuals was $0.4 \%$ (range $0-1 \%$ ) for the maxillary angle and $0.4 \%(0-2 \%)$ for the mandibular angle. Differences between cases and controls were determined with Wilcoxon's rank sum test for paired differences. Significance was taken as $\mathrm{P}<0.05$.

There was no difference in body weight between the cases and controls (5.7 kg (SE 1.0) v $5.7 \mathrm{~kg}(0.5))$. The cases had significantly smaller maxillary angles than the controls (median $82^{\circ}(95 \%$ confidence interval $79^{\circ}$ to $\left.85^{\circ}\right) v 84^{\circ}\left(83^{\circ}\right.$ to $\left.\left.90^{\circ}\right), \mathrm{P}=0.01\right)$. There was a trend for the mandibular angle to be smaller in the cases than in the controls $\left(71^{\circ}\left(67^{\circ}\right.\right.$ to $\left.74^{\circ}\right) v 75^{\circ}$ $\left(70^{\circ}\right.$ to $\left.\left.77^{\circ}\right), \mathrm{P}=0.1\right)$.

\section{Comment}

This study shows that victims of the sudden infant death syndrome had different facial structure compared with control infants, with retroposition of the
Respiratory

Medicine Unit, Department of Medicine, University of Edinburgh, Royal Infirmary, Edinburgh, EH3 9YW Karen Rees, research associate Neil J Douglas, professor of respiratory and sleep medicine

Department of Paediatric Pathology, Department of Medicine, University of Edinburgh Anne Wright, chief medical laboratory scientific officer Jean W Keeling, consultant paediatric pathologist

Correspondence to: Professor Douglas n.j.douglas@ed.ac.uk

BMJ 1998;317:179-80 